\title{
Remoção de herbicida atrazina por meio de filtros de carvão ativado granular associados com microrganismos no tratamento de água para abastecimento
}

\author{
Removal of atrazine herbicide through granular activated carbon filters \\ associated with microorganisms in drinking water treatment \\ Miriam Ruiz Canevaroli' ${ }^{\oplus}$, Eliana Gertrudes de Macedo Lemos ${ }^{2} \odot$, Kelly Mari Pires de Oliveira ${ }^{3} \odot$,

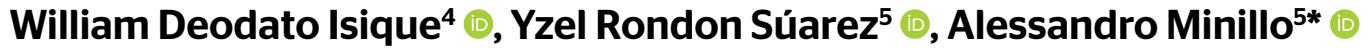

\section{RESUMO}

A atrazina é um herbicida sintético comumente utilizado no controle de ervas gramíneas daninhas e folhagens em lavouras, e é um dos principais contaminantes dos solos e dos ecossistemas aquáticos. Muitos métodos têm sido sugeridos para remover herbicidas da água potável. Contudo, esses métodos são custosos, muitos têm problemas de desempenho, produzem diversos subprodutos intermediários tóxicos, prejudiciais e perigosos. Entretanto, a atrazina é susceptível à degradação por microrganismos presentes na água, no sedimento e no esgoto. Considerando esses aspectos, o objetivo principal do estudo foi investigar a biodegradação e a filtração por meio de filtros de carvão com atividade biológica (CAB) para remoção da atrazina, e sua identificação filogenética associada a esses microrganismos. Os resultados demonstraram que a atrazina foi degradada por microrganismos presentes no biofilme, com remoção superior a $89 \%$ nos filtros CAB. Os microrganismos encontrados integram-se ao grupo das bactérias, composto dos gêneros Acinetobacter, Bacillus, Exiguobacterium e Pseudomonas. Este estudo nos permite inferir sobre a capacidade de biodegradação da atrazina por bactérias presentes nos filtros CAB, a capacidade de remover herbicidas por meio desse sistema de filtros e a possível utilização dessa tecnologia como alternativa para o controle e a remoção dessa substância no tratamento de água.

Palavras-chave: herbicida; bactérias; biofilme; qualidade de água.

\begin{abstract}
Atrazine is a synthetic herbicide commonly used to control weeds and foliage in crops, and is a major contaminants of soil and water ecosystems. Many methods have been suggested to remove herbicides from drinking water. However, these methods are very costly, many have performance problems, produce a lot of toxic intermediates which are very harmful and dangerous. However, atrazine is susceptible to degradation by microorganism present in water, sediment, and sewage effluents. Considering these aspects, the main objective of the study was to investigate the biodegradation and filtration for using biological activated carbon (BAC) filters to remove atrazine, and their phylogenetic identification associated with these microorganisms. The results showed that atrazine was biodegraded by microorganism present in the biofilm, with removal over $80 \%$ in BAC filters. The microorganisms found integrate to the group of bacteria, composed by the genera Acinetobacter, Bacillus, Exiguobacterium, and Pseudomonas. This study allows us to infer the ability to biodegrade atrazine by bacteria present in BAC filters and capacity to remove herbicides by BAC filters, and the possible use of this technology as an alternative for the control and removal of this substance in water treatment.
\end{abstract}

Keywords: herbicides; bacteria; biofilm; water quality.

'Sucocítrico Cutrale - Unidade Colina (SP), Brasil

¿Universidade Estadual Paulista “Júlio de Mesquita Filho" - Jaboticabal (SP), Brasil.

"Universidade Federal da Grande Dourados - Dourados (MS), Brasil.

"Faculdade de Engenharia de Ilha Solteira, Universidade Estadual Paulista "Júlio de Mesquita Filho" - Ilha Solteira (SP), Brasil.

5Universidade Estadual de Mato Grosso do Sul - Dourados (MS), Brasil.

*Autor correspondente: alminillo@yahoo.com.br

Conflitos de interesse: os autores declaram não haver conflito de interesses.

Financiamento: Fundação de Amparo à Pesquisa do Estado de São Paulo (FAPESP).

Recebido: 27/08/2018 - Aceito: 17/01/2020 - Reg. ABES: 20180104 


\section{INTRODUÇÃO}

A expansão da agroindústria tem tornado imprescindível o uso dos agrotóxicos para suprir as crescentes demandas do mercado na produção de alimentos e matérias-primas para as indústrias. Nesse advento, os herbicidas integram uma das classes de compostos químicos utilizados no controle de plantas, especialmente aquelas indesejadas. O molde da agricultura atual depende dos herbicidas para o controle de ervas daninhas, o que promove uma maximização da produtividade das lavouras.

A aplicação dos herbicidas em doses elevadas e, por vezes, desnecessárias sobre diferentes culturas agrícolas tem promovido sua propagação no solo, nos sedimentos, nas águas superficiais e nas águas subterrâneas (VRYZAS et al., 2009). De forma inevitável, a contaminação por herbicidas atinge os mananciais de abastecimento, o que representa um sério risco à saúde humana mediante $\mathrm{o}$ consumo dessas águas sem tratamento adequado (BAGHAPOUR; NASSERI; DERAKHSHAN, 2013).

A atrazina (2-cloro-4-etilamino-6-isopropilamino-s-triazina) (Figura 1) é um herbicida do grupo das s-triazinas, intensamente utilizado no Brasil e no mundo para o controle de ervas daninhas, gramíneas e na agricultura em culturas de milho, cana-de-açúcar e reflorestamentos (OTURAN et al., 2009). A difícil degradação de sua molécula a torna um contaminante de preocupação ambiental em muitos países (GFRERER et al., 2002; CHAN; CHU, 2005), sendo responsável por efeitos cancerígenos em seres humanos (WHO, 2011). Em um levantamento recente realizado sobre a presença desse herbicida em águas doces no Brasil, foram verificadas concentrações de atrazina variando de 0,0027 a 10,4 $\mu$ g.L. $\mathrm{L}^{-1}$ em águas superficiais e de 0,001 a 42,77 $\mu \mathrm{g} . \mathrm{L}^{-1} \mathrm{em}$ águas subterrâneas (DIAS et al., 2018).

No Brasil, a Portaria de Consolidação (PRC) no 5, de 28 de setembro de 2017, Anexo XX, do Ministério da Saúde (MS), define os padrões de potabilidade da água no território nacional, incluindo os valores máximos aceitáveis para a concentração de 38 agrotóxicos diferentes em águas de abastecimento humano (BRASIL, 2017). A despeito, entre os agrotóxicos abordados por essa PRC, encontra-se a atrazina, um herbicida amplamente comercializado no país (IBAMA, 2019).

A ocorrência de atrazina em águas de abastecimento representa um desafio às companhias de saneamento no desenvolvimento de novas tecnologias e melhorias das utilizadas para sua remoção segura em uma estação de tratamento de água (ETA) (CEREJEIRA et al., 2005). Nesse sentido, muitos estudos de bancada recomendam o uso de adsorventes, como carvão ativado, para remoção de herbicidas (atrazina, diuron e hexazinona) e seus subprodutos pós-tratamento em ETAs sem ofertarem riscos à saúde humana (COELHO; DI BERNARDO, 2012; VOLTAN et al., 2016).

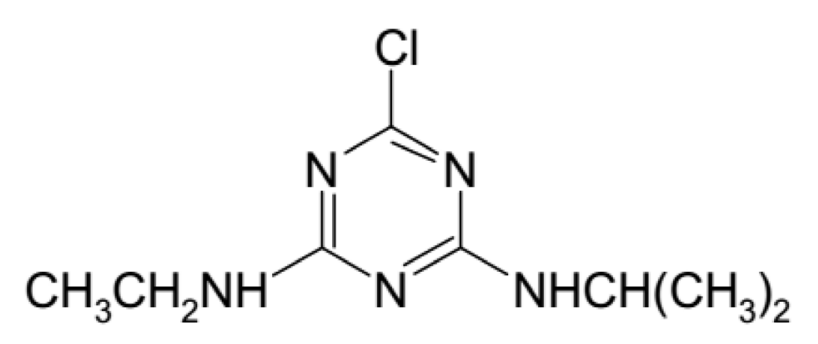

Figura 1 - Estrutura química da atrazina.
O uso do carvão ativado granular (CAG) em sistemas de filtração de ETAs representa uma medida eficaz no tratamento das águas contaminadas por diversos micropoluentes (NAM et al., 2014; ISAAC; FERNANDES, 2017). Contudo, trocas periódicas do carvão no leito filtrante dessas instalações tornam-se necessárias em razão de sua finita capacidade de adsorção das diversas substâncias presentes em águas captadas para abastecimento (SIMPSON, 2008).

Nesse contexto, estudos apontam o uso de filtros de carvão com atividade biológica $(\mathrm{CAB})$ como forma alternativa para manter o padrão de qualidade da água potável, sem encarecer o tratamento da água em ETAs (SERVAIS; BILLEN; BOUILLOT, 1994; SEREDYNSKA-SOBECKA et al., 2006; SIMPSON, 2008). O uso de biofiltros de carvão em ETAs, além de prolongar o tempo operacional das carreiras de filtração, auxilia na remoção de compostos presentes na matéria orgânica (JONES et al., 1998; VAN DER HOEK; HOFMAN; GRAVELAND, 1999; WESTPHALEN; CORÇÃO; BENETTI, 2016) e micropoluentes (e.g., cianotoxinas, herbicidas, fármacos) pelos microrganismos formadores do biofilme (MESQUITA et al., 2006; ZANINI et al., 2014; BORGES et al., 2016).

Considerando o potencial dos biofiltros de carvão em remover poluentes em águas de abastecimento, sem oferecerem maiores riscos na geração de subprodutos nocivos à saúde humana nas águas tratadas, o presente estudo avaliou a capacidade de filtros de carvão colonizados por microrganismos como meio filtrante para a remoção de atrazina, assim como a biodegradação do herbicida por microrganismos aderidos aos filtros, e identificou filogeneticamente a comunidade microbiana presente nesses filtros e que atua no processo de degradação do agroquímico.

\section{METODOLOGIA}

A realização do estudo foi dividida em três etapas distintas:

- Ensaios de biodegradação da atrazina por microrganismos em sistema batch;

- Experimento de remoção do herbicida por meio de filtros de carvão ativado em escala de bancada de laboratório;

- Isolamento e identificação filogenética dos microrganismos associados aos filtros biológicos de carvão.

Para as etapas dos ensaios com a biodegradação, foi utilizada água natural e reconstituída em laboratório, enquanto para os ensaios de filtração, foi usada apenas água natural. A água natural foi coletada em um reservatório próximo, localizado no Bairro Ipê, no município de Ilha Solteira, São Paulo. A área de captação da microbacia da Lagoa do Ipê apresenta aproximadamente 286 ha, de uso urbano-rural, com grande presença de pastagem e cultivos agrícolas anuais e perenes.

A realização dos ensaios de filtração contou com o uso do CAG de casca de coco, com tamanho de grão de 0,35 a $0,50 \mathrm{~mm}$, o qual foi escolhido com base em trabalhos realizados no laboratório de pesquisa (ZANINI et al., 2014; BORGES et al., 2016).

\section{Ensaio 1: experimento de biodegradação da atrazina}

Inicialmente ao ensaio, foi recolhida, em frascos estéreis, uma amostra $(200 \mathrm{~mL})$ dos efluentes de filtros CAB de uma Instalação Piloto de Filtração em Múltiplas Etapas da Faculdade de Engenharia - Campus Ilha Solteira da Universidade Estadual Paulista "Júlio de Mesquita Filho" (FEIS-UNESP), localizada na Lagoa do Ipê. A partir desse efluente colhido, retirou-se uma subamostra $(30 \mathrm{~mL})$, a qual foi utilizada como meio inoculante para os ensaios de biodegradação da atrazina. 
O ensaio de biodegradação do herbicida foi realizado durante 14 semanas, em sistema batch. Para tanto, foram avaliados dois tratamentos distintos: um com água natural e outro com água reconstituída em laboratório, ambas designadas nesta pesquisa como água de estudo. Para os ensaios com água natural, foi utilizada uma água natural coletada na Lagoa do Ipê, que foi filtrada em filtro de celulose $(1,0 \mu \mathrm{m})$, esterilizada $\left(120^{\circ} \mathrm{C}\right.$ por $\left.15 \mathrm{~min}\right)$, com $\mathrm{pH}$ entre $6,8 \mathrm{e} 7,4 \mathrm{e}$ corrigido para 7,9 $\pm 0,1$, e, posteriormente, acrescida do herbicida obtendo concentração final de $10 \mu \mathrm{g} . \mathrm{L}^{-1}$. Para o ensaio com a água reconstituída, foi usada água destilada acrescida de ácido salicílico (1,31 mg. $\left.\mathrm{L}^{-1}\right)$, ácido tânico $\left(1,4 \mathrm{mg} \cdot \mathrm{L}^{-1}\right)$, ácido oxálico $\left(4,2 \mathrm{mg} \cdot \mathrm{L}^{-1}\right)$, ácido húmico $\left(0,8 \mathrm{mg} \cdot \mathrm{L}^{-1}\right)$, ácido acético $\left(4,5 \mathrm{mg} \cdot \mathrm{L}^{-1}\right)$, cloreto de cálcio $\left(0,075 \mathrm{mg} \cdot \mathrm{L}^{-1}\right)$, cloreto de amônia $\left(0,054 \mathrm{mg} . \mathrm{L}^{-1}\right)$, cloreto de potássio $\left(0,055 \mathrm{mg} . \mathrm{L}^{-1}\right)$, com pH corrigido para 7,9 $\pm 0,1$ e, posteriormente, acrescida do herbicida para concentração final de $10 \mu$ g.L. $\mathrm{L}^{-1}$.

O herbicida utilizado no experimento apresentou grau de pureza de 97 a 98\%, segundo fornecedor (Sigma-Aldrich Co Ltd), e confirmado após comparação com padrões comerciais disponibilizados por colaboradores de pesquisas em parceria ao grupo. A água de estudo, de ambos os ensaios, foi acondicionada em galão de vidro (4 L), âmbar e esterilizado (Figura $2 \mathrm{~A}$ ). Ao galão foi inoculado $10 \%(\mathrm{v} / \mathrm{v})$ de uma solução aquosa, filtrada $(1,0 \mu \mathrm{m})$ e contendo os microrganismos do biofilme. Para o tratamento controle, foi usado um galão sob as mesmas condições descritas anteriormente, sem o acréscimo do inóculo com microrganismos, mas com adição de azida de sódio $\left(4 \mathrm{mg} \cdot \mathrm{L}^{-1}\right)$ à água contendo o herbicida, para inibição da atividade biológica dos microrganismos. Os galões foram mantidos no escuro, em sistema fechado, sob agitação orbital (100 rpm) e temperatura aproximada de $23 \pm 2^{\circ} \mathrm{C}$. A cada semana foram recolhidas amostras (100 mL) para leituras do $\mathrm{pH}$ (Digimed DM 20) e quantificação da concentração do herbicida por meio de cromatografia (HPLC - Prominence, Shimadzu).

\section{Ensaio 2: experimento de filtração biológica da atrazina}

Inicialmente, antes da etapa de confecção dos filtros com carvão, foi realizado o cultivo dos microrganismos remanescentes dos ensaios de biodegradação em balões erlenmeyers com meio (3.000 mL) específico composto de glicose (90 mg. $\mathrm{L}^{-1}$ ), peptona (100 mg. $\left.\mathrm{L}^{-1}\right)$, extrato de levedura (100 mg. $\left.\mathrm{L}^{-1}\right)$, acetado de sódio tri-hidratado (70 mg. $\left.\mathrm{L}^{-1}\right)$ e atrazina $(10 \mathrm{mg})$. Posteriormente, foi adicionada uma massa ( $50 \mathrm{~g}$ ) de CAG virgem, o qual foi mantido em agitação orbital (150 rpm) por aproximadamente 7 dias em temperatura controlada $\left(23 \pm 2^{\circ} \mathrm{C}\right)$. A partir desse procedimento, foi promovida a colonização da superfície e do interior do CAG por microrganismos, para posterior confecção dos filtros esse processo de colonização seguiu o protocolo descrito por Mesquita et al. (2006). Medições dos valores do oxigênio dissolvido na água afluente e efluente dos filtros colonizados foram tomadas antes do início dos ensaios para confirmação da atividade biológica dos biofiltros, em comparação com o controle.

Para os ensaios de bancada, foram utilizados seis filtros de carvão ativado confeccionados em colunas de vidro (borosilicato) de $10 \mathrm{~cm}$, com diâmetro interno de $1,2 \mathrm{~cm}$, preenchidos por $3 \mathrm{~cm}$ de uma camada do carvão ativado, aproximadamente $3,5 \mathrm{~g}$ (peso úmido). Três desses filtros, denominados como $\mathrm{CAB}$, foram destinados à filtração com atividade biológica, recebendo água contendo o herbicida na concentração de $10,0 \mu \mathrm{g} . \mathrm{L}^{-1}$. O herbicida utilizado no ensaio possuía padrão de pureza de 97-98\%, conforme descrição do fornecedor (Sigma-Aldrich Co Ltd.). Os outros três filtros foram utilizados como controle, denominados CAG, e desprovidos da colonização por microrganismos. Para inibição de qualquer atividade metabólica dos microrganismos nos filtros CAG, foi adicionada azida de sódio $\left(4 \mathrm{mg} . \mathrm{L}^{-1}\right)$ à água contendo o herbicida. A atividade biológica dos filtros $\mathrm{CAB}$ foi indicada pela taxa de consumo do oxigênio afluente e efluente dos filtros colonizados, em comparação com o controle.

A água utilizada nos ensaios proveio de sua coleta na Lagoa do Ipê, que foi filtrada em filtro de celulose $(1,0 \mu \mathrm{m})$, esterilizada $\left(120^{\circ} \mathrm{C}\right.$ por $\left.15 \mathrm{~min}\right)$, com $\mathrm{pH}$ entre 6,8 e 7,4 corrigido para 7,9 $\pm 0,1$. Os filtros foram mantidos em um fluxo contínuo de água por meio de uma bomba peristáltica multicanais (Ismatec RS $232 \mathrm{IN}$ ). Os filtros foram operados sob fluxo descente com taxa de filtração constante e igual a $3,6 \mathrm{~m}^{3} \cdot \mathrm{m}^{-2} \cdot \mathrm{d}^{-1}$, vazão de $3 \mathrm{~mL} \cdot \mathrm{min}^{-1} \mathrm{e}$ tempo de contato de $12 \mathrm{~min}$ (Figura 2B). O experimento foi realizado durante 70 dias, sendo recolhidas, semanalmente, amostras $(100 \mathrm{~mL})$ afluente e efluente dos filtros, para

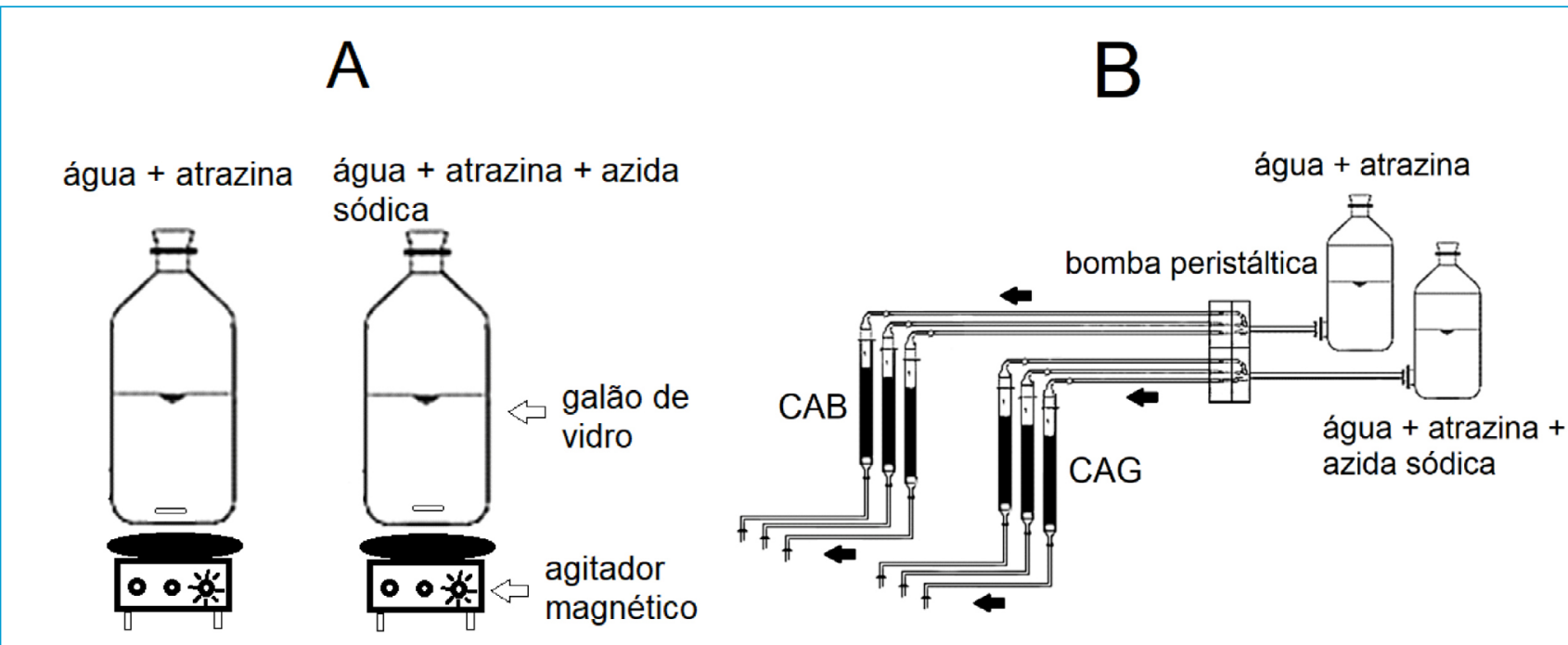

CAB: carvão com atividade biológica; CAG: carvão ativado granular

Figura 2 - Unidades experimentais utilizadas no (A) ensaio 1 de biodegradação e no (B) ensaio 2 de filtração biológica da atrazina em água durante o estudo. 
leituras do pH (DIGIMED DM 20) e determinação do herbicida (HPLC Prominence, Shimadzu).

\section{Ensaio 3: isolamento e caracterização genotípica dos microrganismos nos filtros de carvão com atividade biológica}

Os microrganismos presentes nos filtros $\mathrm{CAB}$ foram submetidos ao processo de isolamento e caracterização filogenética, por meio da retirada de um volume $(1 \mathrm{~mL})$ de amostra na superfície e no interior desses filtros. O material recolhido foi homogeneizado, sendo realizadas diluições decimais de uma alíquota (1 mL) em solução de Ringer para o posterior plaqueamento em meios sólidos contendo meio de cultura ágar padrão para contagem (PCA). As placas foram incubadas a $25^{\circ} \mathrm{C}$, no escuro, por uma semana. Após incubação, foram observadas as principais características das colônias obtidas. $\mathrm{O}$ isolado de cada colônia foi obtido por meio de sucessivos plaqueamentos por esgotamento em estrias e então transferido para tubos de ensaio contendo o meio de cultivo inclinado e mantido em refrigeração a $25^{\circ} \mathrm{C}$. Para cada colônia isolada foram observadas características morfológicas (coloração, tamanho e tipo de borda das colônias), coloração diferencial de Gram, e verificação da formação de esporos (TORTORA; FUNKE; CASE, 2003), de modo a obter informações dos possíveis grupos microbianos presentes nos filtros. Em seguida, foi realizada a produção massiva de cada isolado para extração do DNA e identificação filogenética $(5 \mathrm{~mL})$ utilizando o kit FastDNA SPIN Kit for Soil (BIO 101, Quantum Biotechnologies), seguindo as instruções do fabricante. O gene 16S rRNA do material genético extraído de cada amostra foi amplificado pela técnica de reação em cadeia da polimerase (PCR). Os amplicons gerados foram confirmados por eletroforese em gel de agarose e visualizados em um fotodocumentador (Gel Doc 1000). Os produtos da PCR do gene 16S rRNA foram analisados em um sequenciador de capilar modelo ABI 3700 (Applied Biosystems, Foster City, CA, USA). As sequências foram analisadas com o auxílio do programa Sequencing Analysis 3.4 e pelo programa Phred/Phrap (EWING et al., 1998; EWING; GREEN, 1998), e comparadas com os bancos de dados de genes ribossomais: Ribosomal Database Project II - RDP II (MAIDAK, 2001), por meio do programa Classifir, e National Center for Biotechnology Information - NCBI (SAYERS, 2010), por meio do programa Blast. Todas as sequências do gene $16 \mathrm{~S}$ rRNA obtidas neste estudo foram cadastradas no Banco Internacional de Genes (GenBank).

\section{Análise de atrazina em sistema cromatográfico}

Para a extração da atrazina das amostras, foi utilizada a técnica extração em fase sólida (SPE) em cartuchos com sílica tipo C18 (500 mg - $6 \mathrm{~mL}$ ), conforme metodologia descrita por Talebpour e Bijanzadeh (2007). A separação e a quantificação do herbicida foram realizadas em um cromatógrafo líquido de alta eficiência (Shimadzu), equipado com detector Photodiode Array (SPD-M20A), duas bombas de alta pressão (LC-20AT e LC 20AD), em coluna de fase reversa C-18 (modelo Shim-pack), com 4,6×250 mm e diâmetro de partícula de $5 \mu \mathrm{m}$, segundo Talebpour e Bijanzadeh (2007), com adaptações. A fase móvel foi constituída de metanol e água, sendo a análise realizada em sistema isocrático e o comprimento de onda selecionado de $222 \mathrm{~nm}$. Para cada amostra analisada, em triplicata, foram utilizados fluxo de $1 \mathrm{~mL} \cdot \mathrm{min}^{-1} \mathrm{e}$ tempo de corrida de 18 minutos. A quantificação do herbicida foi efetuada de acordo com o seu respectivo tempo de retenção (TR) e por meio do perfil espectrofotométrico, no comprimento de onda específico de detecção do composto avaliado (Figura 3).

A curva padrão analítica foi obtida por meio do método do padrão interno de atrazina 99\% (Sigma-Aldrich), sendo os teores de atrazina obtidos por meio da plotagem das respectivas áreas por meio da curva padrão. Concomitantemente, o limite de detecção (LD) e o limite de quantificação (LQ) $\left(\mu \mathrm{g} . \mathrm{mL}^{-1}\right)$ também foram obtidos por meio de planilha de validação proposta por Ribeiro e Ferreira (2008).

\section{Análise dos dados}

Os dados obtidos durante o estudo foram armazenados em planilhas eletrônicas e submetidos a análises estatísticas com o teste $t$ de Student, utilizando o Programa Estatístico BioEstat 5.3, sendo avaliado o desempenho de remoção da atrazina pelos microrganismos nos ensaios de biodegradação e nos filtros confeccionados, bem como o comportamento desses frente a outros parâmetros físicos e químicos da água de estudo.

\section{RESULTADOS E DISCUSSÃO}

\section{Biodegradação do herbicida}

Os resultados demonstraram que houve a biodegradação da atrazina nos tratamentos contendo microrganismos, sendo essa acentuada nas três primeiras semanas de ensaio, com redução aproximada de 72 e 62\% para água de estudo natural e reconstituída, respectivamente. Após esse período, houve diminuição na taxa de remoção do herbicida pelos microrganismos, com registros mínimos próximos de $2 \mu \mathrm{g} . \mathrm{L}^{-1}$ nas semanas seguintes. A remoção total do herbicida ocorreu a partir da $12^{\mathrm{a}}$ semana de ensaio. Ao longo de todo o período, verificou-se um comportamento semelhante ao da biodegradação da atrazina pelos microrganismos em ambas as águas de estudo avaliadas, sem qualquer diferença significativa $(\mathrm{p}<0,05)$ entre elas. A degradação natural do herbicida foi verificada e seu comportamento foi semelhante para ambas as águas de estudo, sendo obtidos, ao final do ensaio, valores mínimos próximos de $4 \mu \mathrm{g} \cdot \mathrm{L}^{-1}$.

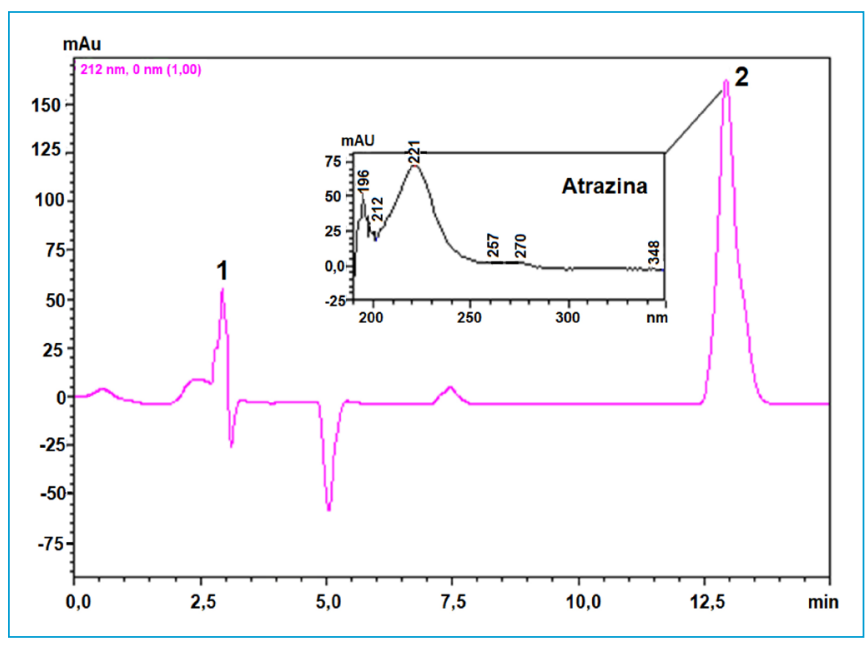

Figura 3 - Perfil espectrofotométrico e cromatográfico de atrazina utilizada no experimento: 1 - Metanol (T.R: 3.01) e 2 - Atrazina (T.R: 12.98). 
Os valores de $\mathrm{pH}$ observados nos ensaios realizados com água natural ficaram ligeiramente acima da neutralidade, com valor médio de 7,65, enquanto a água reconstituída manteve valor próximo da neutralidade (6,9). De modo geral, não foram constatadas, nos ensaios realizados, diferenças significativas $(\mathrm{p}<0,05)$ do $\mathrm{pH}$ registrado entre os tratamentos de controle e com microrganismos. Os resultados referentes à remoção da atrazina pela ação de microrganismos estão sumarizados na Figura 4.

Em concordância com outros estudos realizados com microrganismos (bactérias) como agentes que degradam agrotóxicos em condições laboratoriais (GOVANTES et al., 2009; BAGHAPOUR; NASSERI; DERAKHSHAN, 2013; SOLOMON; KUMAR; SATHEEJA SANTHI, 2013), os resultados do presente estudo demonstraram que a comunidade microbiana contida nos efluentes dos biofiltros da instalação piloto de tratamento de água foi capaz de remover a atrazina a valores abaixo do permitido em água potável (2 $\mu$ g.L. $\mathrm{L}^{-1}$ ) (BRASIL, 2017). Os microrganismos presentes no biofilme dos filtros de carvão indicam que as populações microbianas utilizam plenamente a atrazina como fonte de carbono e nitrogênio para suprir seus gastos energéticos e de seu crescimento (SMITH; ALVEY; CROWLEY, 2005; SHAPIR et al., 2007).

Apesar da total remoção da atrazina pelos microrganismos no presente estudo, o tempo requerido foi relativamente elevado em comparação com trabalhos já realizados utilizando microrganismos isolados de biofilmes (BAGHAPOUR; NASSERI; DERAKHSHAN, 2013; SÁNCHEZ-SÁNCHEZ et al., 2013). Uma possível explicação para o tempo elevado de remoção do herbicida requerido pelos microrganismos no presente estudo talvez decorra da presença de outras fontes orgânicas de carbono na água de estudo, além do próprio agroquímico, que influíram em sua biodegradação. Com o declínio dessas fontes primárias de carbono no meio - essas assimiláveis e de fácil quebra de suas moléculas é provável que os microrganismos passaram a utilizar o herbicida como uma fonte secundária de carbono e energia, o que acarretou (proporcionou) a sua degradação ao longo do tempo. Alguns estudos sobre o potencial de degradação microbiano sugerem que, ao longo do tempo, o declínio da matéria orgânica utilizada pelos microrganismos como elementos nutricionais induz ao uso de compostos xenobióticos (cianotoxinas, fármacos) como fonte de carbono e energia, propiciando sua degradação (MINILLO et al., 2013; BORGES et al., 2016). Uma situação semelhante foi observada por Park et al. (2001), quando verificaram que o tempo de degradação de ficotoxinas (microcistinas) foi quatro vezes superior em um meio suporte contendo essa toxina e nutrientes inorgânicos, quando comparado com um meio experimental contendo apenas a toxina e nutrientes orgânicos.

O processo de metabolização microbiana é reconhecido como um fator crítico e importante que afeta o destino e o comportamento de diversos poluentes (e.g., agrotóxicos) em um ecossistema aquático. A microbiota aquática formada em determinado substrato compreende uma diversidade de espécies de microrganismos integrantes em uma comunidade dinâmica capaz de degradar uma grande variedade de compostos químicos (LÓPEZ et al., 2005). A ausência de dados durante este estudo sobre a mineralização ou biotransformação do herbicida no tratamento avaliado não permitiu definir qual foi o destino final da atrazina, mas foi possível estabelecer que a comunidade microbiana presente nos filtros de carvão promoveu a redução do herbicida para suprir o seu metabolismo. Outro aspecto que deve ser considerado foi a degradação natural sofrida pela atrazina nos ensaios controles. Embora essa tenha ocorrido com valores pouco menores em relação aos tratamentos com microrganismos isolados dos biofiltros de carvão, seus valores devem ser considerados no balanço final de remoção do agroquímico.

\section{Remoção da atrazina com filtros biológicos de carvão}

Os resultados obtidos com o uso do sistema de filtração demonstraram que houve a remoção da atrazina pelos conjuntos de filtros testados (Figura 5A). A remoção com filtros de carvão colonizados por microrganismos (CAB) foi ligeiramente maior em sua média (85,65\%), quando comparada aos valores obtidos utilizando filtros de carvão sem atividade biológica (CAG) (79,63\%). Pode-se verificar que as duas configurações de filtros apresentaram o padrão de expressiva remoção do herbicida, demonstrando que o CAG utilizado, assim como as condições experimentais, foram favoráveis para a elevada capacidade de adsorção da atrazina durante o ensaio.

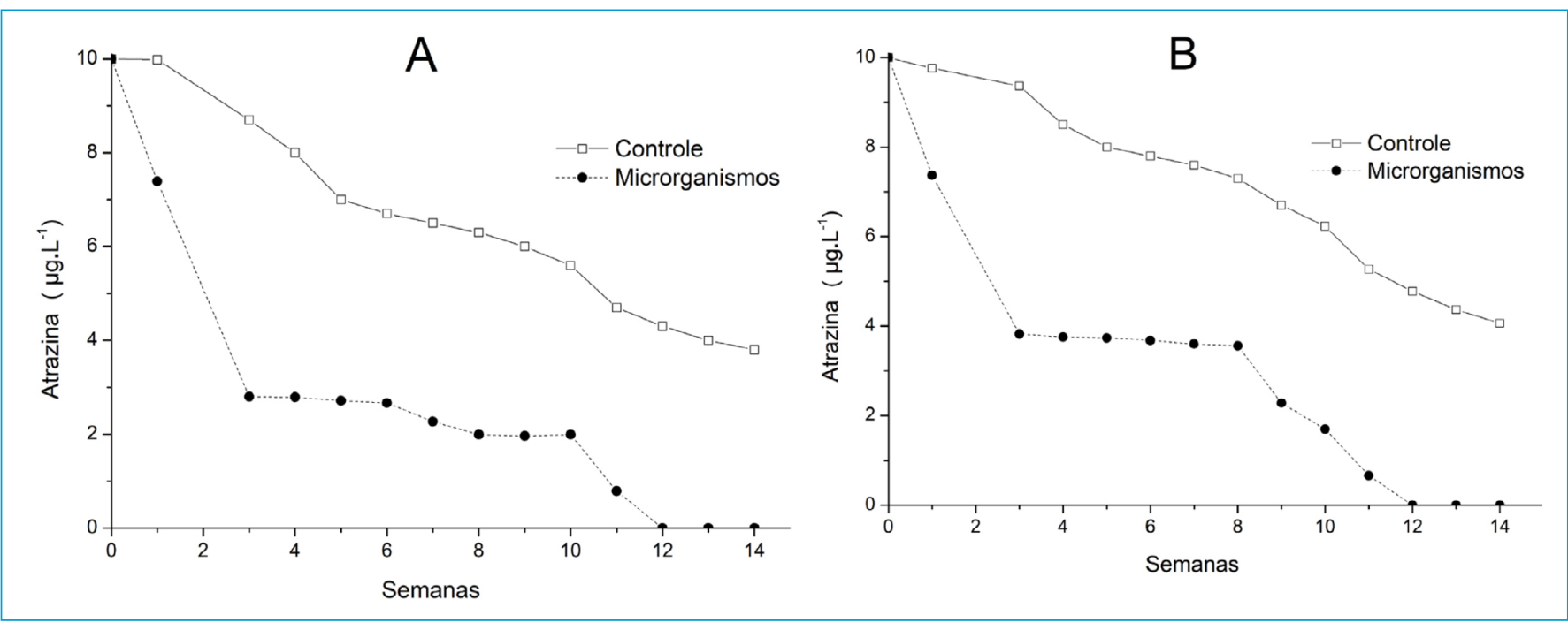

Figura 4 - Valores finais de degradação de atrazina nos ensaios com (A) água natural e (B) água reconstituída realizados durante o estudo. 


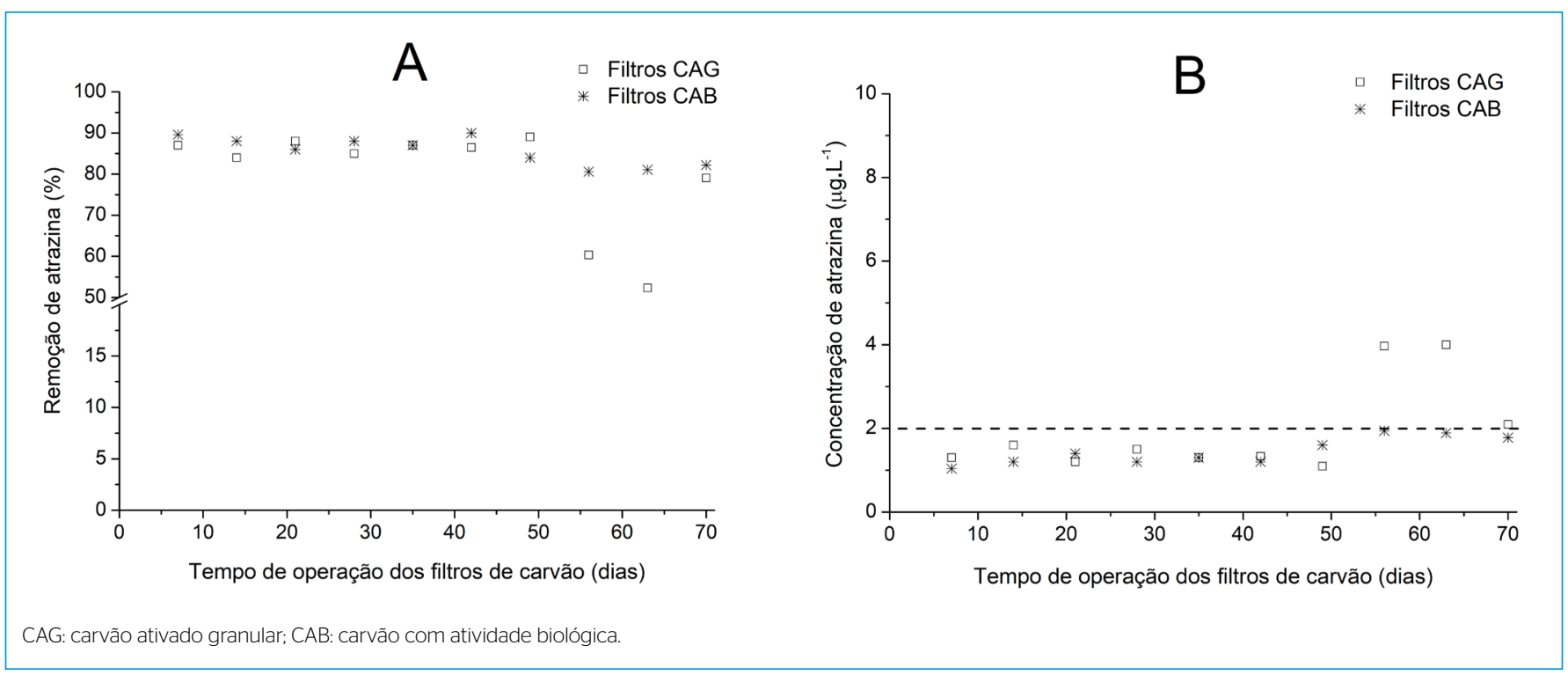

Figura 5 - (A) Valores de remoção (\%) da atrazina obtidos com uso de filtros de carvão com atividade biológica e filtros de carvão ativado granular; e (B) níveis detectados do herbicida nos efluentes dos sistemas de filtros avaliados.

Entre os filtros testados, os valores registrados do $\mathrm{pH}$ mantiveram-se ligeiramente acima da neutralidade para ambos os sistemas, com valores médios entre 7,29 e 7,69 para os filtros com e sem biofilme, respectivamente. De modo geral, nos ensaios realizados, não foram constatadas diferenças significativas $(\mathrm{p}<0,05)$ nos valores registrados nos tratamentos controle e com microrganismos.

Em relação à capacidade de retenção do herbicida utilizando os dois modelos de filtros testados, pôde-se observar, no presente estudo, menor dispersão relativa $(\mathrm{CV}<10)$ aos percentuais de remoção da atrazina utilizando filtros de carvão com biofilme (CAB), com residuais no efluente dos filtros, em média, menores que $2 \mu \mathrm{g} . \mathrm{L}^{-1}$ (Figura $5 \mathrm{~B}$ ). Essa condição possivelmente indica que a combinação simultânea dos processos de biodegradação e adsorção reduziu as flutuações da concentração da atrazina na água afluente, conforme relatado em alguns trabalhos (SEREDYNSKA-SOBECKA et al., 2006; AKTAS; ÇEÇEN, 2007). A despeito dos filtros de carvão sem atividade biológica (CAG), pôde-se constatar dispersão temporal um pouco maior da retenção do herbicida $(\mathrm{CV} \geq 16)$, o que refletiu sobre uma eficiência ligeiramente menor desses filtros no experimento. Pôde-se observar que em amostras do efluente desses filtros, próximo ao final do estudo, os valores de atrazina estavam ligeiramente acima do limite máximo permitido ( $\left.2 \mu \mathrm{g} . \mathrm{L}^{-1}\right)$ pela PRC do MS (BRASIL, 2017) (Figura 5B).

As oscilações na adsorção do herbicida no filtro de carvão durante este estudo podem estar associadas às concentrações desse adsorvato presente no meio (BRADY, 1997). Para uma reação reversível de adsorção, as moléculas do adsorvato acumulam-se no meio de maior concentração (água) para a superfície de menor concentração (carvão); com a queda na concentração do adsorvato no meio (afluente), a taxa de reação de adsorção diminui, gerando menor adsorção do herbicida. Caso ocorra, por um espaço de tempo, uma menor concentração da atrazina no afluente em relação à concentração no carvão, poderá acontecer a reação reversa (dessorção), tornando o herbicida livre para o meio. Contudo, não foi possível comprovar a ocorrência desses efeitos no presente estudo.

O presente estudo estabelece que o uso dos filtros de carvão colonizados por microrganismos pode representar uma alternativa para a remoção de micropoluentes presentes na água de uma ETA. Os microrganismos formadores do biofilme nos filtros de carvão promoveram um efeito complementar na remoção da atrazina, essa decorrente, provavelmente, da biodegradação do herbicida. Esse padrão observado está em concordância com um estudo realizado por Jones et al. (1998) sobre a remoção de atrazina com filtros de carvão inoculados com bactérias. Além disso, a literatura tem demonstrado que a vida útil do carvão em ETAs, dependendo das características da água bruta e do adsorvato, está em torno de 6 a 12 meses (SIMPSON, 2008). A redução da vida útil desse carvão no leito filtrante pode ser observada pela perda significativa na eficiência de adsorção e pelo transpasse de concentrações consideráveis das moléculas adsorvidas para a água (HO, 2004; WANG et al., 2007). Os resultados obtidos no presente estudo reforçam a viabilidade no uso dos filtros de carvão como possível alternativa de emprego para remoção de atrazina em águas contaminadas e destinado ao consumo humano.

\section{Caracterização filogenética dos microrganismos nos filtros de carvão}

A partir do material coletado dos filtros contendo microrganismos, foi possível a obtenção de 12 amostras de microrganismos isolados (Figura 6). O cultivo desses microrganismos isolados, segundo os métodos microbiológicos tradicionais, permitiu a obtenção do material genético para a extração de seu DNA, auxiliando, dessa forma, na maior acurácia na sua identificação.

A partir dos isolados cultivados e da extração do DNA desses microrganismos, foi possível, por meio da análise das sequências do gene 16S rRNA amplificadas, a identificação da presença de um filo (Proteobacteria) distribuído em quatro gêneros distintos: Acinetobacter, Bacillus, Exiguobacterium e Pseudomonas, conforme descrito na Tabela 1.

Com base na análise da diversidade microbiana presente no biofilme dos filtros de carvão, foi constatada a dominância de bactérias do gênero Pseudomonas. Esse gênero de microrganismos tem sido considerado ubíquo, podendo ser isolado em ambientes diversos (solo, água doce, água marinha e alimentos). 


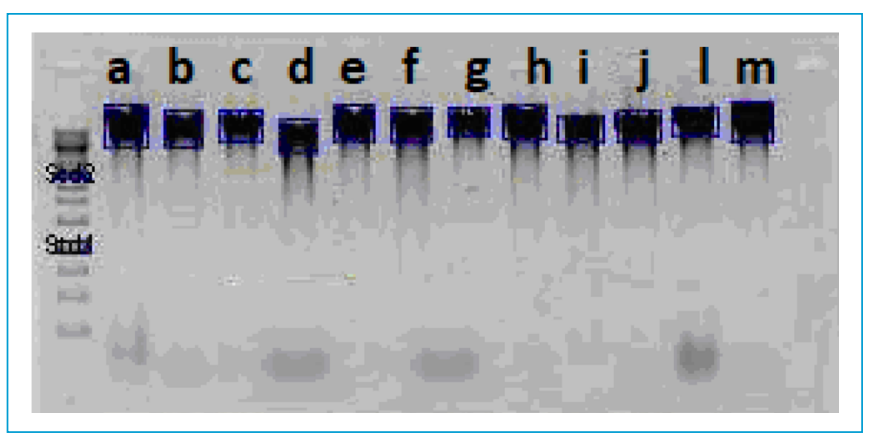

Figura 6 - Corrida eletroforética em gel de agarose dos isolados coletados dos filtros de carvão com atividade biológica.

Tabela 1 - Informações sobre o sequenciamento e o cadastramento das sequências dos genes $16 \mathrm{~S}$ rRNA dos isolados obtidos.

\begin{tabular}{c|c|c|c} 
Isolados & $\begin{array}{c}\text { Acesso ao } \\
\text { GenBank }\end{array}$ & $\begin{array}{c}\text { Similaridade } \\
\text { (organismo) }\end{array}$ & \% similaridade \\
\hline P1 & FJ985793.1 & Acinetobacter $s p$. & 99 \\
\hline P2 & FJ985794.1 & Acinetobacter $s p$. & 99 \\
\hline P3 & FJ985795.1 & Pseudomonas $s p$. & 97 \\
\hline P4 & FJ985796.1 & Bacillus $s p$. & 99 \\
\hline P5 & FJ985797.1 & Exiguobacterium $s p$. & 99 \\
\hline P6 & FJ985798.1 & Pseudomonas $s p$. & 96 \\
\hline P7 & FJ985799.1 & Pseudomonas $s p$. & 99 \\
\hline P8 & FJ985800.1 & Pseudomonas $s p$. & 97 \\
\hline P9 & FJ985801.1 & Pseudomonas $s p$. & 98 \\
\hline P10 & FJ985802.1 & Pseudomonas $s p$. & 98 \\
\hline P11 & FJ985803.1 & Pseudomonas $s p$. & 97 \\
\hline
\end{tabular}

Fonte: dados disponíveis no Banco Internacional de Sequências (NCBI).

Algumas linhagens de Pseudomonas são descritas com amplo espectro em metabolizar compostos orgânicos e sintéticos em matrizes ambientais, o que as tornam foco de diversas pesquisas, principalmente aquelas que tangenciam suas principais vias responsáveis pela degradação de diferentes compostos (SMITH; ALVEY; CROWLEY, 2005). A versatilidade de diferentes linhagens das Pseudomonas em metabolizar substâncias complexas e recalcitrantes, como a atrazina, tornam-nas amplamente descritas na literatura (NEUMANN et al., 2004; ARIOLE; ABUBAKAR, 2015; FERNANDES et al., 2018).

Entre os isolados identificados pelas técnicas empreendidas no presente estudo, também foi possível verificar a presença dos gêneros Acinetobacter e Bacillus. Representantes desses gêneros são descritos em diversos trabalhos envolvendo os mecanismos responsáveis pela degradação de atrazina e de diferentes substratos orgânicos como fonte de carbono, bem como a capacidade de colonização em diversos ambientes, mesmo sobre limitações na oferta de nutrientes (SINGH; SURI; CAMEOTRA, 2004; ARIOLE; ABUBAKAR, 2015). A ocorrência dos diferentes gêneros de bactérias no presente estudo reforça a importância dos consórcios microrganismos no biofilme para o desempenho de remoção do herbicida ao longo dos ensaios de filtração. É possível que tenha ocorrido a interação de processos simultâneos, como a bioadsorção e a biodegradação, para a remoção da atrazina nos ensaios, o que estaria em consonância com outros trabalhos realizados (SEREDYNSKA-SOBECKA et al., 2006; SIMPSON, 2008).

As linhagens bacterianas encontradas no presente estudo fortalecem a evidência de que a biodegradação da atrazina foi um fator importante e atuante para sua remoção nos filtros de carvão com biofilme. A biodegradação é um processo resultante da produção de ampla gama de enzimas hábeis e ativas por microrganismos, mediante sua exposição e adaptação a um determinado composto (LÓPEZ et al., 2005; VIBBER; PRESSLER; COLORES, 2007; SOLOMON; KUMAR; SATHEEJA SANTHI, 2013). Estudos apontam que a exposição prolongada de comunidades microbianas a compostos xenobióticos (e.g., herbicidas) pode facilitar sua biodegradação e, assim, reduzir a toxicidade em locais contaminados (SOLOMON; KUMAR; SATHEEJA SANTHI, 2013). Embora não tenha sido detectada a presença de atrazina nas águas coletadas na Lagoa do Ipê, para a realização dos ensaios, não é descartada a possível contaminação desse ambiente pelo herbicida em períodos remotos, uma vez que nas áreas adjacentes à lagoa são comuns cultivos agrícolas anuais e perenes. Essa condição poderia explicar a aceitação dos microrganismos ao herbicida e sua metabolização verificada ao longo deste estudo. Essa hipótese foi confirmada por Udikovic-Kolic, Scott e Martin-Laurent (2012) ao relatarem que após um período de 30 anos de aplicação de atrazina em ambiente natural, algumas bactérias do solo foram induzidas a mineralizar o herbicida, além de espalharem rapidamente genes sobre outras populações bacterianas com a mesma capacidade de metabolização do composto.

Uma série de microrganismos que degradam parcialmente ou completamente a atrazina foi isolada e, a partir dela, os genes que codificam as enzimas envolvidas na degradação da atrazina. Nos genes de Pseudomonas sp ADP, foi descoberto um par de 108-kb do plasmídeo autotransmissível, pADP-1, completo sequenciado. São descritos três genes (atz $A, \operatorname{atz} B$ e atzC) nesses plasmídeos que codificam enzimas responsáveis pela quebra da atrazina em ácido cianúrico, que estão localizados em uma região instável de plasmídeos. Uma região diferente de $\mathrm{pADP}-1$ contém os genes atz $D$, atz $E$ e atz $F$, que codificam enzimas que fragmentam o anel da molécula de atrazina-triazina e levam à conversão de ácido cianúrico com dióxido de carbono e amônio (VIBBER; PRESSLER; COLORES, 2007).

As bactérias estão entre os organismos que melhor interagem na dinâmica de biodegradação, muitas vezes assumindo o papel central do fenômeno, em razão da sua capacidade de metabolizar uma diversidade de poluentes, enquanto outros organismos (e.g., fungos e protozoários) podem favorecer ou mesmo afetar essa dinâmica (LÓPEZ et al., 2005). Os resultados obtidos no presente estudo e a literatura referenciada permitem inferir que os microrganismos isolados e identificados participaram da ação de degradação do herbicida. O potencial uso desses microrganismos capazes de metabolizar os herbicidas configura uma proposta futura para o tratamento de água, principalmente quando as condições adequadas para a biodegradação puderem ser identificadas e impostas sobre os filtros biológicos.

As citadas literaturas sobre biodegradação da atrazina a partir de grupos específicos de microrganismos auxiliam o conhecimento sobre a importância da capacidade metabólica e as características gênicas das cepas envolvidas na degradação da atrazina. A possibilidade de identificação desse gene representa uma base tecnológica para futuros trabalhos direcionados ao uso de microrganismos para o tratamento biológico de águas contaminadas por agrotóxicos. 
No entanto, há necessidade de estudar a evolução das linhagens comparando a capacidade metabólica e caracterizando os genes envolvidos na biodegradação da atrazina (UDIKOVIC-KOLIC; SCOTT; MARTIN-LAURENT, 2012; SINGH et al., 2018).

A despeito das diversas pesquisas que auxiliam no aumento da eficiência de remoção dos herbicidas em ETAs, o presente estudo estabelece uma possível via de tratamento de água contendo um composto recalcitrante cada vez mais comum nos mananciais de abastecimento do Brasil. Além disso, impera a necessidade de ações que promovam maior conscientização em relação ao uso dos agroquímicos, em conjunto com medidas ostensivas para sua maior fiscalização e adequação de legislações específicas direcionadas ao monitoramento e à qualidade da água potável para a saúde pública com segurança no país. Isso tudo deve, no futuro, ser estendido com o mesmo entendimento para outros compostos xenobióticos.

\section{CONCLUSÕES}

Pôde-se verificar a remoção da atrazina pelos microrganismos presentes em filtros biológicos de carvão, comprovando a metabolização do herbicida pelos componentes microbianos presentes nos biofiltros.

A constatada degradação natural da atrazina, que apesar de reduzida em relação aos tratamentos com microrganismos, não pode ser negligenciada em um balanço final de remoção do agroquímico.
Averiguou-se expressiva remoção da atrazina em ambas as configurações de filtros testadas, com valores ligeiramente maiores nos filtros de carvão colonizados por microrganismos em relação aos filtros de carvão desprovidos de atividade biológica.

A possibilidade de uso e seleção de linhagens específicas de microrganismos capazes de metabolizar a atrazina representa uma proposta para a ativação biológica de leitos de filtros de carvão, bem como a busca por sistemas mais eficientes de tratamento de água, aumentando a eficiência na remoção desses compostos.

O uso de filtros biológicos de carvão representa uma técnica promissora para a remoção da atrazina presente nos mananciais de abastecimento público. Esse sistema poderia viabilizar a aplicação de novas tecnologias para a melhoria da qualidade de águas contaminadas por esses herbicidas.

\section{CONTRIBUIÇÕES DOS AUTORES}

Canevaroli, M. R.: Conceituação, Curadoria de Dados, Investigação, Metodologia, Administração do Projeto, Visualização, Escrita - Primeira Redação. Lemos, E. G. M.: Análise Formal, Metodologia, Supervisão, Escrita - Revisão e Edição. Oliveira, K. M. P.: Conceituação, Investigação, Escrita - Revisão e Edição. Isique, W. D.: Curadoria de Dados, Conceituação, Investigação, Administração, Metodologia. Suaréz, Y. R.: Visualização, Escrita - Primeira Redação, Escrita - Revisão e Edição. Minillo, A.: Análise Formal, Administração, Supervisão, Escrita - Revisão e Edição.

\section{REFERÊNCIAS}

AKTAS, O.; ÇEÇEN, F. Competitive adsorption and desorption of a bio-solute mixture: effect of activated carbon type. Adsorption, v. 13, n. 2, p. 159-169, 2007. https://doi.org/10.1007/s10450-007-9017-5

ARIOLE, C.N.; ABUBAKAR, A. Biodegradation of Atrazine by Bacteria Isolated from Lotic Water. Journal of Applied Life Sciences International, v. 2, n. 3, p. 119-125, 2015. https://doi.org/10.9734/JALSI/2015/14345

BAGHAPOUR, M.A.; NASSERI, S.; DERAKHSHAN, Z. Atrazine removal from aqueous solutions using submerged biological aerated filter. Journal of Environmental Health Science and Engineering, v. 11, n. 6, p.1-9, 2013. https:// doi.org/10.1186/2052-336x-11-6

BORGES, R.M. et al. Uso de filtros de carvão ativado granular associado a microrganismos para remoção de fármacos no tratamento de água de abastecimento. Engenharia Sanitária e Ambiental, v. 21, n. 4, p. 709-720, 2016. https://doi.org/10.1590/s1413-41522016118787

BRADY, R.D. Activated carbon processes. In: AMERICAN WATER WORKS ASSOCIATION (AWWA); AMERICAN SOCIETY OF CIVIL ENGINEERS (ASCE). Water treatment plant design. Nova York: McGraw-Hill, 1997. p. 377-416.

BRASIL. Ministério da Saúde. Portaria de Consolidação n० 5, de 28 de setembro de 2017. Anexo XX. Diário Oficial da União, Brasília, Seção 1, p. 360, 3 out. 2017.

CEREJEIRA, M.J. et al. Pesticides in Portuguese surface and ground Waters. Water Research, v. 37, n. 5, p. 1055-1063, 2005. https://doi.org/10.1016/s00431354(01)00462-6
CHAN, K.H.; CHU, W. Effect of humic acid on the photolysis of the pesticide atrazine in a surfactant-aided soil-washing system in acidic condition Water Research, v. 39, n. 10, p. 2154-2166, 2005. https://doi.org/10.1016/j. watres.2005.03.029

COELHO, E.R.C.; DI BERNARDO, L. Remoção de atrazina e metabólitos pela filtração lenta com leito de areia e carvão ativado granular. Engenharia Sanitária e Ambiental, v. 17, n. 3, p. 269-276, 2012.

DIAS, A.C.L. et al. Ocorrência de Atrazina em águas no Brasil e remoção no tratamento da água: revisão sistemática. Revista Internacional de Ciências, v. 8, n. 2, p. 234-253, 2018. https://doi.org/10.12957/ric.2018.34202

EWING, B.; GREEN, P. Base-calling of automated sequencer traces using Phred II. Error probabilities. Genome Research, v. 8, n. 3, p. 186-194, 1998.

EWING, B. et al. Base-calling of automated sequencer traces using Phred I. Accuracy assessment. Genome Research, v. 8, n. 3, p. 175-185, 1998. https:// doi.org/10.1101/gr.8.3.175

FERNANDES, A.F.T. et al. Degradation of atrazine by Pseudomonas sp. and Achromobacter sp. Isolated from Brazilian agricultural soil. International Biodeterioration \& Biodegradation, v. 130, p. 17-22, 2018. https://doi. org/10.1016/j.ibiod.2018.03.011 
GFRERER, M. et al. Triazines in the aquatic system of Eastern Chinese Rivers Liao-He and Yangtse. Chemosphere, v. 47, n. 4, p. 455-466, 2002. https://doi.org/10.1016/s0045-6535(01)00320-4

GOVANTES, F. et al. Atrazine biodegradation in the lab and in the field: enzymatic activities and gene regulation. Microbial Biotechnology, v. 2, n. 2, p. 178-185, 2009. https://dx.doi.org/10.1111\%2Fj.1751-7915.2008.00073.x

HO, L.S.W. The removal of cyanobacterial metabolites from drinking water using ozone and granular activated carbon. Tese (Doutorado) - University of South Australia, Adelaide, 2004.

INSTITUTO BRASILEIRO DO MEIO AMBIENTE DOS RECURSOS NATURAIS RENOVÁVEIS (IBAMA). Relatórios de comercialização e agrotóxicos. Brasil: Ibama. Disponível em: http://www.ibama.gov.br/agrotoxicos/relatorios-decomercializacao-de-agrotoxicos. Acesso em: 29 out. 2019.

ISAAC, R.L.; FERNANDES, R. Point of use granular activated carbon filters (POU) efficiency for atrazine removal. Multi-Science Journal, v. 1, n. 7. p. 103108, 2017. https://doi.org/10.33837/msj.v1i7.175

JONES, L.R. et al. Bacterial inoculation of granular activated carbon filters for the removal of atrazine from surface water. Water Research, v. 32, n. 8, p. 2542-2549, 1998. https://doi.org/10.1016/S0043-1354(97)00458-2

LOPEZ, L. et al. Identification of Bacteria Isolated from an Oligotrophic Lake. Ecotoxicology, v. 14, n. 3, p. 299-312, 2005. https://doi.org/10.1007/s10646003-6367-y

MAIDAK, B.L.; COLE, J.R.; LIBURN, T.G.; PARKER JR., C.T.; SAXMAN, P.R.; FARRIS, R.J.; GARRITY, G.M.; OLSEN, G.J.; SCHMIDT, T.M.; TIEDJE, J.M. The RDP-II (Ribosomal Database Project). Nucleic Acids Research, v. 29, n. 1, p. 173-174, 2001. https://doi.org/10.1093/nar/29.1.173

MESQUITA, E. et al. MicrocystinLR removal by bench scale biologicalactivated-carbon filters. In: GIMBEL, R.; GRAHAM, J.D.; COLLINS, M.R. (org.). Recent Progress in Slow sand and Alternative Biofitration Processes. Londres: IWA Publishing, 2006. p. 373-383.

MINILLO, A. et al. Biodegradação da hepatotoxina (D-Leu') - MicrocistinaLR por bactérias presentes em filtros biológicos de carvão. Engenharia Sanitária e Ambiental, v. 18, n. 3, p. 205-213, 2013. https://doi.org/10.1590/ S1413-41522013000300003

NAM, S.W. et al. Occurrence and removal of selected micropollutants in a water treatment plant. Chemosphere, v. 95, p. 156-165, 2014. https://doi. org/10.1016/j.chemosphere.2013.08.055

NEUMANN, G. et al. Simultaneous Degradation of Atrazine and Phenol by Pseudomonas sp. Strain ADP: Effects of Toxicity and Adaptation. Applied and Environmental Microbiology, v. 70, n. 4, p. 1907-1912, 2004. https://doi. org/10.1128/aem.70.4.1907-1912.2004

OTURAN, N.; SIRES, I.; OTURAN, M.A.; BRILLAS, E. Degradation of pesticides in aqueous medium by electro-fenton and related methods. a review. Environmental Engineering and Management Journal, v. 19, p. 235-255, 2009.

PARK, H.D. et al. Degradation of the cyanobacterial hepatotoxin microcystin by a new bacterium isolated from a hypertrophic lake. Environmental Toxicology, v. 16, n. 4, p. 337-343, 2001. https://doi.org/10.1002/tox.1041

RIBEIRO, F.A.L.; FERREIRA, M.M.C. Planilha de validação: uma nova ferramenta para estimar figuras de mérito na validação de métodos analíticos univariados. Química Nova, v. 31, n. 1, p. 164-171, 2008. https://doi. org/10.1590/S0100-40422008000100029

SÁNCHEZ-SANCHEZ, R. et al. Removal of triazine herbicide s from aqueous systems by a biofilm reactor continuously or intermittently operated. Journal of Environmental Management, v. 128, p. 421-426, 2013. https://doi. org/10.1016/j.jenvman.2013.05.050

SAYERS, E.W. Basic local alignment search tool. National Center for Biotechnology Information (NCBI), 2010. Disponível em: http://blast.ncbi. nlm.nih.gov/Blast.cgi. Acesso em: 15 jun. 2018.

SEREDYNSKA-SOBECKA, B. et al. Biological activation of carbon filters, Water Research, v. 40, n. 2, p. 355-363, 2006. https://doi.org/10.1016/j. watres.2005.11.014

SERVAIS, P.; BILLEN, G.; BOUILLOT, P. Biological colonization of granular activated carbon filters in drinking-water treatment. Journal of Environmental Engineering, v. 120, n. 4, p. 888-899, 1994. https://doi. org/10.1061/(ASCE)0733-9372(1994)120:4(888)

SHAPIR, N. et al. Evolution of catabolic pathways: genomic insights into microbial s-triazine metabolism. Journal of Bacteriology, v. 189, n. 3, p. 674 682, 2007. https://doi.org/10.1128/JB.01257-06

SIMPSON, D.R. Biofilm processes in biologically active carbon water purification. Water Research, v. 42, n. 12, p. 2839-2848, 2008. https://doi. org/10.1016/j.watres.2008.02.025

SINGH, P.; SURI, C.R.; CAMEOTRA, S.S. Isolation of a member of Acinetobacter species involved in atrazine degradation. Biochemical and Biophisical Research Communications, v. 317, n. 3, p. 697-702, 2004. https:// doi.org/10.1016/j.bbrc.2004.03.112

SINGH, S.J. et al. Toxicity, degradation and analysis of the herbicide atrazine. Environmental Chemistry Letters, v. 16, p. 211-237, 2018. https://doi. org/10.1007/s10311-017-0665-8

SMITH, D.; ALVEY, S.; CROWLEY, D.E. Cooperative catabolic pathways within an atrazine-degrading enrichment culture isolated from soil. FEMS Microbiology Ecology, v. 53, n. 2, p. 265-273, 2005. https://doi.org/10.1016/j. femsec.2004.12.011

SOLOMON, R.D.J.; KUMAR, A.; SATHEEJASANTHI, V.S. Atrazine biodegradation efficiency, metabolite detection, and trzD gene expression by enrichment bacterial cultures from agricultural soil. Journal of Zheijang University Science B, v. 14, n. 12, p. 1162-1172, 2013. https://doi.org/10.1631\%2Fjzus.B1300001

TALEBPOUR, Z;; BIJANZADEH, H.R. A selective 19F NMR spectroscopic method for determination of insecticide diflubenzuron in different media. Food Chemestry, v. 105, n. 4, p. 1682-1687, 2007. https://doi.org/10.1016/j. foodchem.2007.05.001

TORTORA, G.J.; FUNKE, B.R.; CASE, C.L. Microbiologia. São Paulo: Artmed, 2003

UDIKOVIC-KOLIC, N.; SCOTT, C:; MARTIN-LAURENT, F. Evolution of atrazinedegrading capabilities in the environment. Applied Microbiology and Biotechnology, v. 96, n. 5, p. 1175-1189, 2012. https://doi.org/10.1007/s00253-0124495-0

VAN DER HOEK, J.; HOFMAN, J.; GRAVELAND, A. The use of biological activated carbon filtration for the removal of natural organic matter and organic micropollutants from water. Water Science and Technology, v. 40, n. 9. p. 257-264, 1999. https://doi.org/10.1016/SO273-1223(99)00664-2 
VIBBER, L.L.; PRESSLER, M.J.; COLORES, G.M. Isolation and characterization of novel atrazine-degrading microorganisms from an agricultural soil. Applied Microbiology and Biotechnology, v. 75, n. 4, p. 921-928, 2007. https:// doi.org/10.1007/s00253-007-0871-6

VOLTAN, P.E.N. et al. Predição da performance de carvão ativado granular para remoção de herbicidas com ensaios em coluna de escala reduzida. Engenharia Sanitária e Ambiental, v. 21, n. 2, p. 241-250, 2016. https://doi. org/10.1590/s1413-41522016138649

VRYZAS, Z. et al. Spatial and temporal distribution of pesticide residues in surface waters in northeastern Greece. Water Research, v. 43, n. 1, p. 1-10, 2009. https://doi.org/10.1016/j.watres.2008.09.021

WANG, $H_{\text {.; }} \quad \mathrm{HO}$, L.; LEWIS, D.M.; BROOKES, J.D.; NEWCOMBE, G. Discriminating and assessing adsorption and biodegradation removal mechanisms during granular activated carbon filtration of microcystin toxins. Water Research, v. 41, n. 18, p. 4262-4270, 2007. https://doi. org/10.1016/j.watres.2007.05.057

WORLD HEALTH ORGANIZATION (WHO). Atrazine and Its Metabolites in Drinking water. Genebta: WHO, 2011. 15 p.

WESTPHALEN, A.P.C.; CORÇÃO, G.; BENETTI, A.D. Utilização de carvão ativado biológico para o tratamento de água para consumo humano. Engenharia Sanitária e Ambiental, v. 21, n. 3, p. 425-436, 2016. https://doi. org/10.1590/S1413-41522016143108

ZANINI, J. et al. Remoción del herbicida atrazina utilizando la combinación de filtros lentos de arena y filtros con carbón activado granular. Revista Técnica de la Facultad de Ingeniería Universidad del Zulia, v. 37, n. 2, p. 125134, 2014 